\title{
APLICABILIDADE DA TEORIA DO CAOS A ORGANIZAÇÕES
}

\author{
VIEIRA, Ernesto Jose ${ }^{1}$ \\ MARTINS, Henrique Cordeiro ${ }^{2}$ \\ GONÇALVES, Carlos Alberto
}

\begin{abstract}
RESUMO: Este trabalho procura verificar se existem elementos típicos da Teoria do Caos em organizações, assim como se a visão, missão e objetivos consistem em atratores que evitam que a bifurcação ou ponto de ruptura se instale. Para responder à estas perguntas, tornou-se necessário incluir nesta pesquisa um objetivo geral além dos específicos. Como suporte desenvolveu-se um referencial teórico sobre Teoria do Caos. Esta teoria apresenta um sistema com uma ordem em uma aparente aleatoriedade, com padrões - comportamentos que ocorram mais de uma vez, ao longo do tempo. Em seguida abordou-se a metodologia que classificou-se como qualitativa, por meio de um estudo exploratório para avaliação de dez empresas da Grande Belo Horizonte. Analisou-se os dados obtidos nas entrevistas quando conclui-se que os resultados observados validaram as proposições iniciais.
\end{abstract}

Palavras-Chave: Teoria do caos. Controle de rupturas. Ponto de bifurcação. Missão e objetivos.

\section{APPLICABILITY OF CHAOS THEORY IN ORGANIZATIONS}

SUMMARY: This study seeks to verify if there are typical elements in Chaos Theory in organizations as well as to verify if vision, mission, and objectives consist of attractors which prevent the installation of bifurcation or chaos rupture. In order to respond to these questions, it was necessary to include in this study general in addition to specific objectives. As a support a theoretical reference on Chaos Theory was developed. This theory presents a system with order within an apparently random system with patterns - behaviors which occur more than once, through time. The qualitative methodology utilized exploratory study. Ten companies within Metropolitan Belo Horizonte were studied. The results validated the initial theoretical propositions.

Keywords: Chaos theory. Rupture controls. Bifurcation point. Mission and objective. Objetivos generales y específicos

RESUMEN : En este trabajo se trata de determinar si existen elementos típicos de la teoría del caos en las organizaciones, así como la visión, misión y objetivos consisten en atractores que impiden bifurcación o punto de ruptura instalar. Para responder a estas preguntas, se hizo necesario incluir en este estudio un objetivo general más allá específico.Como apoyo desarrollado un marco teórico sobre la Teoría del Caos.Esta teoría se presenta un sistema con un orden aparentemente aleatoria con las normas - comportamentos que ocurre más de una vez en el tiempo. Entonces-se dirigió a la metodología que se clasifica como cualitativa, a través de un estudio exploratorio para evaluar diez empresas de Gran Belo Horizonte. Se analizaron los datos obtenidos de entrevistas cuando se llegó a la conclusión de que los resultados observados validan las declaraciones iniciales.

Palavras-chave: La teoría del caos. Cortes de control. Punto de bifurcación. Misión y objetivos.

\section{INTRODUÇÃO}

Segundo Morgan (2009), as teorias da administração incorporaram os conhecimentos da física newtoniana, originando modelos de organização, vistos como máquinas, adequados ao ambiente estável das primeiras décadas do século XX. Entre as décadas de 1930 e 1960, incorporaram-se os conhecimentos

\footnotetext{
${ }^{1}$ Mestre pela universidade FUMEC. professor do centro universitário UNA

2 Doutor em Administração pela UFMG, Professor da Universidade FUMEC

${ }^{3}$ Doutor em Administração pela Universidade de São Paulo. Professor da Universidade FUMEC
} 
da Sociologia e da Biologia, originando os chamados modelos orgânicos, que consideram a influência do ambiente e a necessidade de flexibilidade interna da organização, para se adaptar e evoluir em ambientes mutáveis. A partir das décadas de 1960 e 1970, o crescimento dos mercados aumentou a competição entre as organizações, que têm enfrentado o desafio de tentar acompanhar a dinâmica de seus ambientes. Esta dificuldade se deve a dois fatores: primeiro, estão sempre procurando condições de funcionamento que as levem à estabilidade e à regularidade, acreditando que o êxito do negócio depende do equilíbrio por meio da adaptação às mudanças do ambiente; segundo, acredita-se também que as decisões e ações conduzam aos resultados previstos (EISENHARDT; SCHOONHOVEN, 1990).

Segundo Mariotto (2003), pressionadas pela competição intensificada, as organizações têm, cada vez mais, buscado flexibilidade, inovação, habilidades múltiplas, descentralização e novos usos para a tecnologia de informação e comunicação, assumindo, frequentemente, novos formatos. Uma complexidade crescente caracteriza os ambientes internos e externos, enfrentados pelas organizações. $\mathrm{O}$ que a ciência contemporânea vem demonstrando, por meio das teorias do caos e da complexidade, é que tanto o equilíbrio quanto a previsibilidade são exceção e não regra (MATOS; ALMEIDA, 2007). A própria vida organizacional é um fenômeno complexo, instável e imprevisível, e, portanto, deve ser tratada sob uma perspectiva condizente com esta realidade (EISENHARDT; SCHOONHOVEN, 1990). Modelos utilizados amplamenteem sistemas lineares, no passado, não são eficazes em sistemas complexos, imprevisíveis e irregulares.

A Teoria do Caos fornece uma explicação para estes sistemas não lineares, propiciando um melhor entendimento do equilíbrio entre ordem e desordem (GUO; VOGEL; ZHOU; ZHANG; CHEN, 2009). Wilber (2007) sustenta que a Teoria do Caos está ligada à descoberta de padrões e leis razoavelmente simples, que governam uma série de fenômenos complexos. Para esse autor, a Teoria do Caos destrói o mito da previsibilidade e controlabilidade, sem apresentar soluções para o problema da previsão, mas mostrando os limites para sua tratabilidade.

Assim, esta pesquisa questiona a existência de existirem elementos típicos da Teoria do Caos nos processos de planejamento em organizações, assim como se a visão, missão e objetivos consistem em atratores que evitam que a bifurcação ou ponto de ruptura se instale. Como sustentação a estas questões criou-se o objetivo de analisar a aplicação da teoria do Caos nas organizações, além dos específicos de analisar os conceitos da Teoria do Caos, e sua aplicação em organizações. Como suporte a estes objetivos cria-se uma estrutura teórica que é apresentada a seguir, em revisão da literatura.

\section{REVISÃO DE LITERATURA}

\section{Teoria do caos}

Giovannini e Kruglianskas (2004) sustentam que é perigoso analisar a gestão de organizações, partindo-se de abordagens compartimentalizadas, uma vez que todos os processos e participantes das organizações possuem algum tipo de interdependência. Levam-se em consideração as dinâmicas em operação no sistema global e que, portanto, um mundo sistêmico não pode ser entendido pelo exame exclusivo de acontecimentos ou indivíduos isolados (WHEATLEY, 2006).

Prigogine (1996), ao reconhecer o papel das flutuações e da instabilidade no mundo moderno, revela que as escolhas múltiplas se adaptam melhor às previsibilidades limitadas de curto prazo. Fazendo menção à Física tradicional, o autor relembra que, para essa ciência, desde que fossem dadas condições iniciais apropriadas, estaria garantida a previsibilidade do futuro. Assistiu-se, então, ao surgimento de uma ciência que não mais se limita a situações simplificadas, idealizadas, mas que nos põe diante 
da diante da complexidade do mundo real.

Segundo Freitas (2005), a visão de Newton gera nas pessoas um padrão de pensamento que tende à simplificação. Esta visão simplista do mundo está sendo substituída por outra, essencialmente complexa e paradoxal. Comparando o pensamento mecanicista com o pensamento sistêmico, a ciência cartesiana acreditava que, em qualquer sistema complexo, o comportamento do todo podia ser analisado por meio de suas partes. Mas a ciência sistêmica mostra que as partes só podem ser entendidas dentro do contexto total.

Guo et al. (2009) advogam que os modelos organizacionais que, no passado, foram utilizados amplamente, não são eficazes em sistemas complexos, imprevisíveis e irregulares. A Teoria do Caos apresenta um sistema com uma ordem em uma aparente aleatoriedade, tendo sido descoberta pelo trabalho de Lorenz, em dinâmica de fluidos, por meio do trabalho de previsão do tempo, em 1961.

A ciência contemporânea, segundo Matos e Almeida (2007), vem demonstrando que as teorias do caos e da complexidade são mais regra do que exceção. Esse entendimento vem permitir uma melhor compreensão das dinâmicas organizacionais nos contextos de forte turbulência, bem como permitir que as organizações se tornem capazes, não apenas de conviver com a turbulência, mas de tirar partido dela, para evoluir a partir de sistemas complexos.

\section{Entropia e sistemas dissipativos}

Na teoria do caos, salienta-se a importância da entropia ou Segunda Lei da Termodinâmica: sistemas abertos, que se envolvem com seu ambiente, continuam a crescer e a se desenvolver, tendendo para a diversidade e para a complexidade. A Segunda Lei da Termodinâmica estabelece que os sistemas fechados aumentem a entropia, por não interagir com o ambiente, tendendo, espontânea $\mathrm{e}$ irreversivelmente, a um estado de desordem (FREITAS, 2005). No equilíbrio termodinâmico, a entropia tem seu valor máximo quando o sistema está isolado, nas situações próximas do equilíbrio. $\mathrm{O}$ estado estacionário corresponde, então, a um mínimo da produção de entropia.

A entropia representa a quantidade de desordem de um sistema, isto é, quanto mais organizado o sistema, menor é a sua entropia. A entropia cresce em sistemas fechados, que possuem, portanto, uma tendência para se desgastarem, dissipando uma energia que não pode mais ser recuperada (FREITAS, 2005). O modo de compensar essa degradação de um sistema, proveniente da entropia, segundo Bauer (2008), é por meio das trocas de energia com o meio ambiente, ou seja, pelo comportamento como sistema aberto.

No equilíbrio, a produção de entropia é nula e, no regime linear, ela assume seu valor mínimo. Longe do equilíbrio, a matéria adquire novas propriedades, em que as flutuações e as instabilidades desempenham um papel essencial. Assim, a matéria torna-se mais ativa. Nas proximidades do equilíbrio, existe uma produção de entropia mínima, e quando esta produção aumenta, aumentam também as estruturas dissipativas (FREITAS, 2005).

Um sistema dissipativo é a medida de sua ruína, é a rapidez com que a entropia é produzida. Esses distúrbios podem criar desequilíbrio, mas podem também levar ao crescimento, se o sistema tiver a capacidade de reagir e de se alterar. O desequilíbrio, que é uma condição necessária ao crescimento de um sistema, recebe o nome de estrutura dissipativa, uma vez que dissipa a sua forma para se recriar em novas formas (WHEATLEY, 2006). Tais sistemas dissipativos passam a apresentar maior complexidade, que se traduz em um maior volume de interações com seus ambientes e internamente. As estruturas dissipativas demonstram que a desordem pode ser uma fonte de nova ordem, e que o crescimento surge do desequilíbrio, e não do equilíbrio.

Nas organizações, rupturas e caos não precisam ser interpretados como sinais de destruição, mas 
como fonte da criatividade. Os cientistas descrevem a relação, entre a desordem e a ordem, como ordem a partir do caos, ou ordem por meio da flutuação (BAUER, 2008). As estruturas dissipativas, segundo Matos e Almeida (2007), exercem seu papel destrutivo, pois podem inviabilizar o funcionamento do sistema, mas, ao mesmo tempo, exercem um papel potencialmente positivo, pois permitem ao sistema aprender e reorganizar-se.

A organização é caracterizada, simultaneamente, por ordem, à medida que congrega repetição, regularidade e redundância, e é capaz de autorregulação, para a preservação de estabilidades. A dissipação é também capaz de produzir desordem, uma vez que gera perturbações, desvios, ruídos e instabilidades. Essa desordem pode ser de natureza estritamente objetiva (os eventos, desvios e ruídos efetivamente produzidos) ou subjetiva (incerteza quanto ao futuro).

\section{Mudanças e ponto de bifurcação}

Matos e Almeida (2007) advogam também que a concepção das organizações como sistemas sujeitos a perturbações, mas tendentes ao equilíbrio por adaptação a essas perturbações, enfatiza apenas um único tipo de mudança, a incremental, ou passo a passo. Entretanto, as mudanças incrementais não têm conseguido acompanhar as mudanças ambientais abruptas, exatamente como as que, cada vez mais, estão ocorrendo atualmente. Em mercados extremamente competitivos e complexos, em que atualmente as organizações operam, é importante criar um ambiente que impulsione o compromisso de seu pessoal com a mudança.

Segundo Matos e Almeida (2007), nesses mercados competitivos e complexos, o equilíbrio constitui um caso particular e pouco frequente. Para a Teoria do Caos, a desordem, a instabilidade e o acaso constituem a norma e a regra. O sistema procura interagir com o ambiente externo sempre de acordo com uma lógica que prioriza a afirmação de sua identidade, ainda que, para isso, deva estar permanentemente atualizando-a.

A interação de um sistema com seu ambiente externo é reflexo de sua própria organização, é parte de seu padrão circular de interações. Assim, o sistema procura interagir com o ambiente externo sempre seguindo uma lógica que procure facilitar sua autoprodução, ou seja, a preservação de sua identidade (MATOS; ALMEIDA, 2007). A dissipação de um sistema pode chegar a um limiar crítico e irreversível, chamado ponto de bifurcação.

Este ponto de bifurcação é definido, segundo Mcbride (2005), como uma mudança qualitativa no comportamento do sistema dinâmico. Podem ocorrer grandes flutuações nesse comportamento, quando um sistema chega a uma nova alternativa de estado. Tal mudança no estado é irreversível, podendo ser rápida. Após o ponto de bifurcação, o comportamento do sistema torna-se desnorteado, por algum tempo, mas tende a estabilizar-se em um novo equilíbrio, só que qualitativamente distinto do original. $\mathrm{O}$ novo sistema em equilíbrio apresenta novos modos de organização, estruturalmente mais complexos e evoluídos. A partir do ponto de bifurcação, é impossível prever o caminho evolutivo do sistema.

Ckeik (2008) exemplifica um ponto de bifurcação com um sólido, que é aquecido quando suas moléculas vibram, com o acréscimo de energia pressionando contra suas ligações, e forçando a expansão. Quanto mais calor, mais expansão. Não obstante, a certa temperatura e pressão, a transformação em estado líquido torna-se súbita e descontínua. Durante essa fase de instabilidade, o sistema experimenta inúmeras variantes de futuros possíveis, antes de decidir-se por seu novo patamar, estável, de complexidade (MATOS; ALMEIDA, 2007). 


\section{Estrutura fractal}

Wheatley (2006) sustenta que um sistema vivo se modifica para preservar a si mesmo, afirmando que as companhias, organizadas em torno de uma forte identidade, constituem uma forma de autorreferência, criando maior estabilidade e autonomia. A presença de uma identidade clara torna a organização menos vulnerável ao ambiente, e ela desenvolve uma liberdade maior para decidir como reagir. As companhias podem ser sensíveis ao ambiente, mantendo uma ampla abertura às novas oportunidades e empreendimentos compatíveis com as suas habilidades específicas. A autorreferência é o fator que facilita a mudança bem ordenada, no interior de sistemas, em ambientes turbulentos. Não é obtida por meio da obediência a um conjunto exaustivo de padrões e regras, mas a partir de umas poucas regras simples, pelas quais todos são responsáveis, operando-se numa condição de liberdade individual.

Quando existe uma identidade clara em uma organização, ela orienta seus funcionários, mesmo em circunstâncias caóticas, uma vez que as pessoas podem tomar decisões coerentes.

Wheatley (2006) postula também que as organizações têm natureza fractal em termos de comportamentos autossemelhantes. Existem padrões semelhantes que as pessoas exibem, seja num encontro com operários ou numa reunião com executivos. A ordem sempre se apresenta na forma de padrões que se desenvolvem ao longo do tempo. Pode-se definir um padrão como qualquer comportamento que ocorra mais de uma vez. Para a visualização de como os processos caóticos revelam a ordem inerente a um sistema, é preciso mudar o foco de visão das partes para o todo. Quando nos concentramos em momentos individuais, vemos somente o caos. Porém, se dermos um passo atrás e olharmos o que está tomando forma, vemos a ordem, por meio de padrões (WHEATLEY, 2006).

Segundo Giovannini e Kruglianskas (2004), existe uma relação de escala entre os níveis de estruturas fractais, isto é, na relação entre a dimensão do padrão de um nível superior sobre o imediatamente inferior. Esta relação é constante entre todos os níveis de uma estrutura. Uma organização pode ser representada por suas unidades de negócios que, por sua vez, possuem seus setores, que possuem seus departamentos, e assim por diante, até o indivíduo. A abordagem fractal, ou de autossemelhança, abarca toda a estrutura, em termos das ramificações que a produzem, ramificações que se comportam de maneira coerente, das grandes às pequenas escalas (CKEIK, 2008).

Segundo Anselmo (2005), a palavra fractal teve como origem a palavra latina fractus e o verbo frangere, cujo significado é "quebrar em frações". Fractais são formas geométricas encontradas em diversos sistemas naturais, cuja característica é de que a forma das partes se relaciona com o todo. Segundo Bauer (2008), a fractalidade dá ao caos um sentido cíclico, algo como uma repetição para dentro de si mesmo. Este autor afirma que os fractais não apresentam dimensões exatas, nem simetrias perfeitas, e são, portanto, irregulares. Assim como o fractal, o atrator é outro elemento importante na teoria do caos.

\section{Atrator}

Por atrator, entende-se um conjunto invariante, para o qual órbitas próximas convergem depois de um tempo suficientemente longo, isto é, valores para os quais tendem os valores resultantes de um sistema dinâmico não linear, após certo número de ciclos (Giovannini \& Kruglianskas, 2004).

Atrator estranho, segundo Wheatley (2006), é a forma na qual os movimentos caóticos do sistema se auto-organizaram. Seu comportamento é exibido num espaço matemático abstrato, chamado espaço de fase. Seus movimentos respeitam uma fronteira oculta, que é revelada gradualmente. Anselmo (2005) postula que atrator é o conjunto sobre o qual se move um ponto, que representa o estado de um sistema dinâmico, determinista, quando aguardamos certo tempo. O conceito de atrator estranho cria a condição para se compreender melhor o equilíbrio dinâmico e suas implicações para a evolução dos sistemas dinâmicos, não lineares. Apesar das dificuldades de compreensão do que está por trás deste fenômeno, os 
atratores estranhos indicam, porém, uma condição de equilíbrio procurada pelo sistema. A procura dessa condição é garantida pela recursividade dos mecanismos de feedback dos sistemas (GIOVANNINI; KRUGLIANSKAS, 2004).

Smith (2002) sustenta que um atrator pode ser definido como positivo ou negativo. É positivo quando está em um estado no qual o sistema se move em direção a ele; é negativo quando está em um estado em que o sistema se move de forma a evitá-lo.

Freitas (2005) advoga que o atrator estranho é uma posição preferida pelo sistema, em que este evolui na direção daquele, isto é, o comportamento do sistema fica confinado aos limites do atrator. A dinâmica, que atua no interior desses sistemas, os atrai para certos tipos mais prováveis de comportamentos. Os sistemas complexos funcionam por meio de feedbacks positivos e negativos. Quando são afastados do equilíbrio, eles, automaticamente, aplicam restrições internas (feedbacks negativos), para manter a instabilidade dentro de limites. Os processos de feedbacks positivos ampliam e disseminam distúrbios, instabilidades. No limite, eles podem tornar o sistema instável. Mas, nos sistemas complexos, apesar de aparentemente instáveis, seus comportamentos permanecem circunscritos a certos limites, devido a estes atratores estranhos.

Entender o comportamento de um sistema, segundo Mcbride (2005), envolve a reconstrução de seus atratores, não sendo esses estados estáveis, mas padrões temporários de comportamento, que podem mudar a qualquer momento. $\mathrm{O}$ comportamento de uma organização pode, potencialmente, assumir uma das muitas direções, como mudar para um novo atrator estranho, quando essa organização está no limiar do caos.

\section{Limiar do caos, dependência sensitiva as condições iniciais e irreversibilidade}

O limiar do caos é um ponto de não equilíbrio, no qual fatores críticos, relacionados à organização, estão prontos para forçar a mudança para um novo atrator estranho. Nesse ponto, o sistema pode mudar para um novo estado qualitativo, no qual se expressa um novo comportamento emergente, que pode ser descrito em termos de um novo atrator estranho, e essa mudança pode ser vista como uma fase de transição (MCBRIDE, 2005). Essas instabilidades, que provocam mudanças, são reconhecidas como ruídos, que, segundo Giovannini e Kruglianskas (2004), são influências ou instabilidades que os sistemas dinâmicos não lineares podem absorver, apesar da Dependência Sensitiva às Condições Iniciais (DSCI).

Freitas (2005) sustenta que sensibilidade às condições iniciais é uma característica do comportamento dos sistemas complexos, adaptativos ou não. Ela é responsável por sua imprevisibilidade, pois o sistema pode ser sensível até mesmo a minúsculas variações no valor de suas condições ou de seus parâmetros. Este conceito coloca em xeque o princípio de causa e efeito, ação e reação, pelo qual esses dois eventos seriam dependentes em magnitude. Em sistemas não lineares, pequenas causas podem gerar grandes efeitos. Um pequeno desvio nas condições iniciais tem efeitos consideráveis em longo tempo.

Anselmo (2005) considera a irreversibilidade dos fenômenos caóticos como uma questão relevante, pois, na medida em que não se pode reproduzir a totalidade das condições do universo, não se pode garantir a reversibilidade às condições iniciais. Uma das características comuns aos sistemas dinâmicos não lineares é a existência de níveis críticos em uma ou mais de suas variáveis, acima dos quais um pequeno aumento nessas variáveis torna o sistema instável. Essa propriedade dos sistemas dinâmicos não lineares delimita o ponto entre a estabilidade e a instabilidade, tendo reflexos sobre a aplicação nas organizações. Estes sistemas dinâmicos não lineares podem se auto-organizar. 


\section{Auto-organização}

O estudo da auto-organização de sistemas complexos se desenvolveu a partir das pesquisas de Prigogine (1996), Prêmio Nobel de Química, sobre as chamadas estruturas dissipativas. Essas estruturas são sistemas complexos que se auto-organizam, trocando energia com o ambiente, ou seja, diminuem sua entropia com o passar do tempo. Tal descoberta é o contrário da Segunda Lei da Termodinâmica, que postula que, em sistemas fechados, a entropia tende a crescer com o passar do tempo, levando o sistema a uma desordem crescente. Apesar da troca de energia com o ambiente, a estrutura e a dinâmica dos sistemas complexos lhes conferem uma maior capacidade de resistir às influências do meio externo. Tal capacidade decorre de seu processo de aprendizado, que lhe permite se auto-organizar a partir de mudanças no ambiente externo, facilitando sua evolução.

Segundo Anselmo (2005), a auto-organização, ou organização espontânea, é um tipo especial de propriedade emergente de sistemas adaptativos complexos, em que o sistema se organiza sem a intervenção de um controle central. Quando as interações entre um grande número de agentes envolvem sequências de feedbacks positivos, algumas regras de comportamento se reforçam, eliminando outras. Este autor postula que sistemas complexos desenvolvem uma ordem global, que emerge das interações locais, sem que qualquer esforço externo seja necessário. Essa ordem emergente não acontece por meio do processo de seleção natural, no qual uma configuração mais adaptada ao ambiente sobrevive, em detrimento da menos adaptada, mas por meio de um mecanismo espontâneo de auto-organização das partes do sistema, que encontra uma nova configuração estável.

A auto-organização, segundo Bauer (2008), é um processo circular e recorrente, por natureza, que realimenta a si próprio. A autopoiesis, capacidade de auto-organização, faz com que sistema e ambientes forjem-se mutuamente. Autopoiesis é um termo grego que significa autoprodução ou autoformação. A auto-organização eficaz tem como pontos de apoio uma clara noção de identidade, e, o outro, a liberdade. Nas organizações, se as pessoas forem livres para tomar suas próprias decisões, guiadas por uma clara identidade organizacional, que lhes sirva de referência, o sistema, como um todo, desenvolve uma coerência. A organização é menos controladora, porém, mais ordenada (WHEATLEY, 2006).

O potencial para que uma empresa se torne auto-organizante, segundo Bauer (2008), reside em suas redes informais de interação entre as pessoas. Novas tecnologias também vêm abrindo novos horizontes nesse sentido, por meio da eletrônica, que automatiza as interações entre as pessoas, como o correio eletrônico, a videoconferência, a agenda eletrônica.

Em se tratando da complexidade, segundo Giovannini e Kruglianskas (2004), os componentes do sistema tendem a se auto-organizar quando oferecidas informações sobre o todo e possibilidade de comunicação e interação intensas. Essas informações, comunicação e interação são as formas que assumem os mecanismos de feedback.

\section{Feedback e mudanças}

Os mecanismos de feedback, ou ciclos de retro informação, segundo Wheatley (2006), assinalam os desvios em relação à meta estabelecida. Os gerentes realizam uma função semelhante quando avaliam o desempenho, de acordo com critérios-padrão, ou comparam o progresso com determinado plano. A informação é usada para ajudar o sistema a alcançar resultados predeterminados. O sistema é retroalimentado com algum tipo de informação sobre o resultado de suas ações e, com base nessa informação, o sistema ajusta suas ações posteriores. O feedback pode provocar reações que reforçam as ações do sistema ou as amortecem (GIOVANNINI; KRUGLIANSKAS, 2004).

Estes ciclos retroativos, segundo Freitas (2005), rompem o princípio da causalidade linear, uma vez que, durante as interações mútuas entre causa e efeito, a causa age sobre o efeito e o efeito sobre a 
causa. Essa recursividade tem dois aspectos: um regulador, denominado feedback negativo, que impede que os desvios destruam os sistemas; e outro amplificador, chamado de feedback positivo, que os faz evoluir. Esta recursividade, segundo Giovannini e Kruglianskas (2004), é a reaplicação, no sistema, das mesmas regras, ciclo após ciclo. O mecanismo de feedback, baseado na mútua causalidade dos sistemas não lineares, amplifica o efeito de pequenas alterações. Segundo estes autores, uma vez que o principal elemento dos sistemas organizacionais são as pessoas, que são os agentes do sistema, os circuitos de feedback estão acoplados, criando, portanto, um sistema tipicamente não linear, sendo que, nesses circuitos de feedback, quem toma as decisões são os agentes do sistema, isto é, as pessoas. É, na situação intermediária, entre desordem e ordem, no limiar do caos, que uma organização pode, simultaneamente, produzir a estabilidade necessária à condução eficiente de suas atividades de rotina e a instabilidade necessária à emergência da mudança. A imprevisibilidade dos sistemas caóticos significa inovação contínua nas empresas, geração de novos produtos e serviços.

O comportamento não linear, característico dos sistemas complexos, é aquele cuja resposta a um determinado estímulo não é, necessariamente, proporcional à intensidade desse estímulo. $\mathrm{O}$ efeito feedback quebra a linearidade de tal forma que a causa age sobre o efeito, e o efeito age sobre a causa, tornando-se causador ao retroagir sobre a causa. Nos sistemas complexos, não é possível construir o sistema, como um todo, por meio da soma de suas partes. Estes sistemas possuem estrutura não linear, em virtude de os seus componentes, e o ambiente onde se inserem, estarem interligados por processos de feedbacks recursivos, fazendo com que, ao longo do seu funcionamento, pequenas perturbações sejam ampliadas, quebrando o vínculo entre entrada e a saída subsequente (FREITAS, 2005).

Bauer (2008) advoga que os circuitos de feedback negativo predominam se a grande maioria das pessoas, ou agentes, aceitarem as regras, normas e procedimentos vigentes, realizando suas escolhas não de forma arbitrária, mas sempre em conformidade com regras. Nesse caso, o sistema, como um todo, se comporta de forma previsível, e será atraído para algum estado de equilíbrio. Ao contrário, se o comportamento da grande maioria dos agentes não guardar vínculo com essas regras, predominarão os circuitos autoamplificáveis de feedback positivo, e o sistema caminhará para a desordem, num estado de não equilíbrio.

A resposta de muitos problemas está em entender como se comporta o sistema, que tipo de feedback existe, de que forma esse feedback atua e o tipo e duração dos ciclos de retroalimentação. Essa resposta não reside na busca de mais informações para se encontrar uma relação de causa-efeito, que permita fazer previsões e controlar os sistemas (GIOVANNINI; KRUGLIANSKAS, 2004).

A recursividade dos sistemas dinâmicos não lineares provoca a relação desproporcional entre causa e efeito e é intrínseca, independendo de fatores externos. O mecanismo de feedback, baseado na mútua causalidade dos sistemas não lineares, amplifica o efeito de pequenas alterações (GIOVANNINI, KRUGLIANSKAS, 2004).

Esses autores sustentam que agentes submetidos a pequenas alterações, algumas provenientes do próprio ambiente que estão criando, levam à situação de mútua causalidade, envolvendo agentes sobre o sistema e o sistema sobre os agentes, provocando fenômenos característicos que estão no foco central da complexidade.

A cibernética mostra como, por meio dos mecanismos de feedback, ou retroalimentação, sistemas mecânicos, orgânicos e sociais conseguem ter um comportamento autocontrolado e direcionado a algum tipo de objetivo. Em determinados sistemas dinâmicos, a incerteza e o caos são gerados internamente, pelo próprio sistema, devido à sua não linearidade, e não exclusivamente por fatores externos. A complexidade e o caos podem surgir de regras relativamente simples, aplicadas continuamente de forma recursiva. 
Bauer (2008) sustenta que o sistema complexo ou não linear tem se tornado mais frequente no contexto organizacional. Esse autor advoga que estamos acostumados com a mudança incremental, sendo que esses modelos não têm conseguido acompanhar mudanças que adquirem caráter de descontinuidade. Nos fenômenos caóticos, não existe, na dinâmica organizacional, uma proporcionalidade causa-efeito, duradoura no tempo. Como expresso no conceito de horizonte temporal, as pessoas e os grupos, em uma organização, podem escolher, planejar e controlar suas próprias ações, mas não podem escolher, planejar ou controlar os desdobramentos futuros dessas ações. As mudanças lineares, implicando em causa-efeito, não estão atendendo à dinâmica da ambiência contemporânea.

\section{Aplicabilidade da teoria do caos as organizações}

Necessitamos pensar, não mais em termos de uma linearidade causa-efeito, mas em termos de uma circularidade recursiva, em que uma dada causa gera efeitos que atuam de forma causal sobre outros efeitos que, simultaneamente, atuam todos sobre a causa original em questão. Os agentes geradores de causas, como as partes constitutivas de uma empresa, são as pessoas, não só dotadas de livre-arbítrio, como também sujeitas à coerção de outrem, e cujo comportamento é, portanto, imprevisível. As pessoas reagem de forma desproporcional aos estímulos recebidos, devido ao fato de elas não tratarem os estímulos em si, mas as percepções subjetivas que obtêm desses estímulos. Assim sendo, as interações humanas constituem circuitos de feedback não linear (BAUER, 2008).

Muitos ex-defensores do planejamento propõem, hoje, o termo pensamento estratégico, acentuando que as organizações exigem novas habilidades, como agilidade e inteligência para responder à barragem incessante de mudanças frequentes e não planejadas, não se tratando, porém, de sugerir que as organizações existam num estado totalmente reativo. Em vez da capacidade de analisar e prever, precisamos saber aprender melhor, e com mais rapidez (WHEATLEY, 2006).

Os arranjos humanos nas organizações, segundo Bauer (2008), são sistemas interativos e recursivos que podem exibir mudanças descontínuas ao longo do tempo, tal qual os sistemas caóticos. Uma empresa é uma instância dinâmica que evolui no tempo por meio de interações complexas entre governo, trabalhadores, consumidores, instituições financeiras e outras empresas. Nos sistemas lineares, o todo é igual à soma das partes, ao contrário dos sistemas não lineares. Devido ao seu caráter evolutivo, fruto da sinergia entre as pessoas, que gera um todo maior do que a soma das partes, os sistemas humanos são tidos como não lineares.

Ao contrário do que ocorre em sistema não linear, o relacionamento entre um fator ambiental e comportamento do sistema, em sistemas lineares, é previsível e facilmente modelável. Quando a presença do fator ambiental cresce, o comportamento do sistema muda linearmente em resposta. O comportamento em sistema caótico é imprevisível, com períodos de inatividade, mudanças bruscas, padrões de comportamento que podem desaparecer, e novos padrões que podem surgir. O sistema caótico não indica falta de ordem, mas dinamismo e frequente instabilidade. Tais comportamentos aperiódicos são complexos e permanentemente sensíveis a pequenas perturbações. A Teoria do Caos se refere a um estudo qualitativo de comportamento aperiódico e instável em sistemas determinísticos dinâmicos e não lineares. É uma parte da teoria da complexidade, relativa a sistemas dinâmicos não lineares, que não seguem padrões previsíveis e repetitivos (MCBRIDE, 2005).

Segundo Giovannini e Kruglianskas (2004), a incerteza é inerente aos sistemas dinâmicos não lineares e ela não é eliminada, nem necessariamente diminuída, com um maior controle sobre os parâmetros do sistema. Em se tratando de um sistema dinâmico não linear, que possui características similares às das organizações, como um todo, uma característica importante a ser considerada é a da adaptabilidade, isto é, a capacidade de aprender com a experiência e alterar seu comportamento com base 
nela, e outra característica é a de ser um sistema aberto, mais especificamente, uma estrutura dissipativa, isto é, que absorve e posteriormente dissipa recursos do ambiente.

Segundo Wilber (2007), a Teoria do Caos destrói o mito da previsibilidade e controlabilidade. Bauer (2008) advoga que, se conseguirmos precisar o comportamento do sistema, em um instante, será possível prever com exatidão seu comportamento para os instantes próximos, porque os efeitos de feedback entre eventos muito próximos são desprezíveis. Já para períodos mais longos, os efeitos acumulativos dos vários tipos de feedback, que compõem a dinâmica global do sistema, tornam-se bastante significativos, o que depõe a favor da adoção de modelos de planejamento em tempo real, ou planejamento por fluxo, no lugar dos modelos tradicionais de planejamento por ciclos. Um planejamento por fluxo seria orientado à adaptabilidade; o planejamento por ciclos, a objetivos preestabelecidos.

Em longo prazo, imprevisibilidade de sistemas caóticos não significa inexistência de qualquer padrão. Da mesma forma, segundo Freitas (2005), não podemos confundir a existência de padrões e leis com possibilidade de previsão. O padrão de uma organização é uma configuração de relações características de um sistema em particular. A Teoria do Caos é o estudo destes padrões e leis, razoavelmente simples, que governam o comportamento dos sistemas complexos, denominados dinâmicos, significando que evoluem com o passar do tempo, sendo não lineares, pois a resposta não é proporcional ao estímulo aplicado, isto é, o estudo de uma série de fenômenos complexos.

$\mathrm{O}$ estudo da Teoria do Caos procura também identificar padrões em comportamento, mantendo o foco nas mudanças qualitativas. O caos está ligado à descoberta de padrões e leis razoavelmente simples, que governam uma série de fenômenos complexos (WILBER, 2007). Segundo Freitas (2005), os sistemas caóticos são determinísticos, tal que, uma vez dada a condição inicial, existe somente um único ponto ou objetivo que pode ser matematicamente atingido. Pequenas mudanças nas condições iniciais podem gerar muitos pontos finais diferentes. Em muitos sistemas, a complexidade é aumentada, uma vez que existe constante intervenção envolvendo novas condições e mudanças ambientais.

Caos e complexidade, segundo Giovannini e Kruglianskas (2004), não estão relacionados ao fato de haver muitas alterações ou variáveis no ambiente de negócios, e de ser impossível conhecer e controlar todas elas. Esta visão pressupõe que, se houvesse recursos suficientes para conhecer e controlar essas variáveis, seria possível prever o comportamento e dirigir com precisão os sistemas organizacionais. É uma típica visão determinístico-mecanicista, adequada a sistemas complicados, que são diferentes de sistemas complexos. Um sistema dinâmico não linear, segundo Thietart e Forgues (1995), é um sistema em que as relações entre as variáveis dependentes do tempo mudam, de forma não linear. A instabilidade pertencente a sistemas dinâmicos e não lineares pode levar à mudança e, esta, à evolução.

A evolução, segundo Matos e Almeida (2007), não se faz linearmente, mas com rupturas, quando há uma acumulação de energia, se estabilizando em uma nova ordem ou em torno de outro atrator. A evolução é composta por rupturas e crises, sendo, ao mesmo tempo, caótica e ordenada. Portanto, a ordem coexiste com a desordem, ambas se equilibrando e conferindo uma dinâmica. A Teoria do Caos determinístico busca entender a ordem que surge espontaneamente por trás da desordem.

Essas flutuações que levam ao caos são um processo necessário para a criação de uma nova ordem. Essa nova ordem nos transmite, muitas vezes, o sentido de que os fatos estão fora de controle, mas esse sentido não passa de dificuldades que temos em compreender uma realidade mais profunda da vida organizacional. Em se tratando da Teoria do Caos, devemos pensar mais sobre estruturas, fluidas e orgânicas, que sobre as mecânicas. Devemos reconhecer as organizações como sistemas inteiros, creditando-lhes algum tipo de capacidade de auto-organização. O sistema caótico não indica falta de ordem, mas dinamismo e frequente instabilidade, renovação, percebendo que as pessoas têm a capacidade de 
se organizar sozinhas (WHEATLEY, 2006).

A impossibilidade de previsão em longo prazo se dá em virtude da dependência e sensibilidade às condições iniciais. Mesmo flutuações microscópicas, ou pequenas variações, em um sistema dinâmico e complexo, podem levar a grandes mudanças, podendo chegar a mudanças súbitas ou rupturas (HUNG; TU, 2009).

Essas mudanças súbitas ou rupturas, segundo Matos e Almeida (2007), são provenientes de uma instabilidade maior no sistema, provenientes de pequenas perturbações aleatórias, amplificadas pelo efeito de feedback, que leva o sistema até um limite denominado ponto de bifurcação. Após o ponto de bifurcação, o comportamento do sistema torna-se desnorteado por algum tempo, mas tende a estabilizar-se em um novo equilíbrio, mas qualitativamente distinto do original. O novo sistema em equilíbrio apresenta novos modos de organização, estruturalmente mais complexo e evoluído.

Wheatley e Rogers (2000) sustentam que as organizações podem se valer da redundância, da imprecisão, de densas teias de relacionamentos e de uma incansável cadeia de tentativas e erros para descobrir quais opções funcionam. A simultaneidade reduz os efeitos de qualquer erro, desde que os elementos não estejam ligados sequencialmente. As colônias de bactérias localizam seu alimento enviando batedores aleatórios, cada um com um número grande de bactérias.

Bertalanffy (2008) considera outra forma de organização, com os conceitos de propósito ou objetivo, e de globalismo ou totalidade. Quanto ao propósito ou objetivo proporcional, funciona como um atrator em empresas caóticas. Todo sistema tem um ou alguns propósitos específicos dentro de sistemas maiores. As partes ou elementos do sistema, bem como os relacionamentos entre essas partes, definem uma estrutura que visa sempre a um propósito ou finalidade a alcançar. Quanto ao globalismo, todo sistema deve ser estudado em sua totalidade, pois o todo é diferente do somatório das partes. Devido à interdependência entre estas partes, um estímulo em qualquer parte do sistema afetará todas as outras. O efeito total desse estímulo provocará uma reação global do sistema. Assim, podemos dizer que os sistemas possuem propriedades que suas partes não possuem isoladamente.

Giovannini e Kruglianskas (2004) advogam que somente mudando de atrator, operando constantemente no espaço de transição de fase, é que os sistemas conseguiriam sobreviver e, ao mesmo tempo, garantir a geração de alternativas para evoluir, se tiverem autonomia para tal. As características dos sistemas dinâmicos não lineares são especialmente críticas após certo número de ciclos. À medida que nos afastamos do início do sistema, maior é a incerteza. A cada ciclo, pequenas diferenças iniciais têm uma influência cada vez maior no resultado. Quando o sistema se aproxima dos seus limites, a relação entre as variáveis se altera sensivelmente, amplificando a incerteza e gerando o comportamento caótico.

\section{Caos deliberado ou emergente}

Matos e Almeida (2007) sustentam que o caos pode ser deliberado ou emergente. Quando emergente, é inesperado e pode requerer uma ação não prevista na forma de improvisação. O modelo do caos emergente suscita habilidades para a resolução de problemas, conforme eles vão surgindo. O modelo do caos deliberado promove a criação deliberada desde cedo, no princípio, ao levantar questões que podem surgir mais tarde, ao se concentrar na procura e na identificação de problemas em potencial, antes que ocorram, para que possam ser eliminados, mitigados ou resolvidos, com a preparação prévia adequada.

À medida que o sistema evolui em direção a estados de maior complexidade e ordem, segundo Wheatley (2006), o sistema também altera o ambiente. Nenhum dos dois deixa de ser atingido pelas mudanças que ocorrem no outro. Os cientistas denominam este fato como coevolução. As organizações e os seus ambientes evoluem simultaneamente rumo a uma maior adequação mútua. Nessa visão da 
evolução, o sistema muda, o ambiente muda, e mesmo as regras da evolução se alteram.

Segundo Anselmo (2005), os sistemas adaptativos complexos assumem estados críticos de equilíbrio dinâmico, no limite do caos, que lhes permitem ajustar-se às mudanças do ambiente. $\mathrm{O}$ estado tradicional de equilíbrio, no qual um desvio é corrigido e o sistema retorna ao seu estado original, não é adequado para a sobrevivência de sistemas que operam em ambientes dinâmicos. No estado de equilíbrio dinâmico, os agentes individuais buscam se ajustar às mudanças no ambiente.

Porém, tais ajustes individuais se inter-relacionam, originando um processo de coevolução. $\mathrm{O}$ estado de equilíbrio dinâmico decorre dos processos de feedbacks positivos entre os agentes do sistema. Em face de tais feedbacks, pequenas alterações no comportamento desses agentes, ou grupos locais de agentes, podem originar pequenos, médios ou grandes impactos no sistema como um todo. Os sistemas adaptativos complexos se movem na direção do limite do caos, pois essa situação lhes confere vantagens em relação aos sistemas que não a possuem, conseguindo adaptar-se melhor às mudanças do ambiente $\mathrm{e}$ evoluir.

Segundo Giovannini e Kruglianskas (2004), os sistemas organizacionais que sobrevivem e evoluem são mais compreendidos se se considerar que podem ser vistos como estruturas fractais, com autossemelhança entre suas partes, relacionadas segundo leis de escala; e que operam em estabilidade dinâmica em torno de atratores estranhos, que podem mudar de posição em função da capacidade adaptativa.

\section{METODOLOGIA}

O presente trabalho pode ser classificado como qualitativo, uma vez que tem natureza descritiva, obtida através de levantamento bibliográfico sobre o tema, com a leitura e o fichamento do material conseguido.

A pesquisa foi realizada por meio de um estudo exploratório. Durante este estudo, foram entrevistadas dez empresas. Essas entrevistas ocorreram em segmentos industriais, logísticos e de transporte, selecionados em função de suas atividades serem turbulentas, estarem em crescimento, e operarem em mercados altamente competitivos. As respectivas razões sociais dessas empresas foram substituídas por siglas, para manter o sigilo. Essas empresas foram entrevistadas por meio de seus dirigentes, que foram selecionados como depoentes pela indicação de funcionários da própria empresa. Esses funcionários indicaram os respectivos dirigentes como os executivos mais adequados para responder às perguntas previamente apresentadas.

Todos os depoentes responderam às mesmas quatro perguntas, que, no caso da empresa PE, se desmembraram em duas perguntas adicionais. As quatro perguntas utilizadas estão abaixo relacionadas.

As respostas foram comentadas e relacionadas à fundamentação teórica da Teoria do Caos.

1-AC: beneficiamento e comercialização de produtos siderúrgicos, 56 funcionários.

2 DI : fábrica de tintas, 50 funcionários.

3-AR: estudos e planejamento logísticos em transportes industriais. Empresa em fase de crescimento, 100 funcionários. Bases em Contagem, São Paulo, Belém e Macapá.

4-VN: transporte de passageiros urbano e metropolitano, fretamentos, especiais, transporte escolar, 800 funcionários.

5-KB: usinagem e caldeiraria de peças para siderurgia e mineração, 250 funcionários. 
7-EG: projetos e fabricação de máquinas hidráulicas, 50 funcionários.

8-TI: comercialização e industrialização de tubos de aço, 48 funcionários

9-EL: projeto e fabricação de equipamentos eletromecânicos para controle e automação industrial e produtos para condução de energia elétrica. Empresa em fase de crescimento, com 75 funcionários. 10-PE: fabricação de perfiz e estruturas, 250 funcionários.

\section{ANÁLISES DE DADOS}

Apresentação e análise de cada pergunta elaboradas, seguidas dos depoimentos mais relevantes bem como respectivas analises:

Pergunta 1:como os dirigentes entendem a turbulência ou a palavra caos na empresa?

Nesta primeira abordagem, de dez perguntas com oito respostas, seis foram direcionadas para a falta de controle: uma como momento de turbulência e, outra, com fatos acontecendo simultaneamente. Portanto, houve uma maior incidência sobre o entendimento de caos como falta de controle. Notam-se indícios de que os dirigentes sentem que a falta de controle pode levar ao caos irreversível ou ponto de bifurcação.

Pergunta 2: Quais os indicadores e seus limites para manter a empresa dentro do equilíbrio dinâmico?

Evidencia-se que existem indicadores que previnem o ponto de bifurcação ou a irreversibilidade, respondendo ao pressuposto de que existem elementos típicos da Teoria do Caos nas empresas dinâmicas e não lineares, e variáveis controláveis que podem prevenir o ponto de bifurcação ou ruptura.

Reforçando o parecer sobre os pontos de equilíbrio, um diretor presidente afirmou que seu principal indicador é a rentabilidade, acrescentando que a empresa necessita ficar atenta a sua rentabilidade, para continuar os ajustes necessários. Enfatizou a importância da flexibilidade com os números, assim como achar os pontos de equilíbrio entre o custo e a receita, para não deixar que o caos se instale (Sic).

Das dez empresas, todas possuem indicadores, mesmo que simplórios, como vendas, entrada de pedidos, e custos operacionais; três possuem indicadores mais sofisticados, uma delas está tentando desenvolver indicadores para analisar tendências.

Pode-se entender que esta abordagem de análise de tendência é reconhecida como previsibilidade, o que não é possível em empresas complexas e não lineares, em função da Dependência Sensitiva às Condições Iniciais (DSCI), responsável pela imprevisibilidade no comportamento dos sistemas complexos (FREITAS, 2005; ANSELMO,2005).

Nesta abordagem, a maior incidência é de que os executivos utilizam ou pretendem utilizar indicadores para controlar o que entendem por caos na empresa.

Pergunta 3: Como manter a empresa em equilíbrio dinâmico, crescendo, tendo rentabilidade superior à média, gerando valor, sem entrar em um caos irreversível?

Evidencia-se claramente a utilização de indicadores para manter a empresa em equilíbrio dinâmico, evitando o ponto de ruptura, ou bifurcação.

Entende-se que estas empresas mantém o equilíbrio dinâmico por meio dos resultados de indicadores e respectivos ajustes. 
Um empresário advoga que existe um fator importante, que é a falta de motivação ou a falta de sonho, seja do empresário, seja das pessoas que compõem a administração da empresa, ou seja, da própria pessoa física. Se você deixa de sonhar, a possibilidade de você ter insucesso e fazer com que aquela parte econômica da empresa da sua vida deixe de existir é muito grande (Sic).

Pergunta: PE 3-a Este dirigente já teve a ideia de dividir estes sonhos, visões e objetivos na empresa?

Sim, na realidade você não pode ter sonhos distantes porque você vive num mundo moderno e muito dinâmico. Às vezes, posso pensar que, fazendo doce, vou ficar economicamente muito bem. Mas, quando encontro com uma mídia dizendo que doce engorda, isso torna, assim, o negocio inviável. Portanto, temos que ter flexibilidade para colocar outro sonho em ação (Sic).

Esta resposta motivou a pergunta 3-b.

Pergunta: PE 3-b Este depoente acredita que esse sonho possa ser compartilhado, unindo pessoas para uma mesma direção ou objetivo, dentro de uma mesma situação caótica?

Sim, você tem que mostrar para as pessoas que todos estão num mesmo barco e, se não remarmos na mesma direção, não chegaremos a lugar nenhum (Sic).

As abordagens 3-a e 3-b evidenciam a possibilidade de utilizar missão, valores, culturas como atratores estranhos nas organizações (BAUER, 2008; DRAFT; LENGEL, 2001; MORGAN, 2000)

Procurando entender como as empresas mantêm o crescimento, com rentabilidade, evitando o caos, nota-se que, das dez empresas, seis utilizam indicadores, do mais simples, como investimento e caixa, a um conjunto mais complexo.

Pergunta 4: os funcionários são incentivados a trabalhar com mais sinergia, cooperativamente, para a manutenção do equilíbrio dinâmico, evitando o caos irreversível?

Os três dirigentes que responderam à pergunta reconheceram que o trabalho em equipe e a sinergia entre os funcionários ajudam a manutenção do equilíbrio dinâmico em empresas complexas não lineares. A produtividade de pessoas trabalhando em grupo, com sinergia, é potencialmente maior que a soma de seus esforços, se tomados individualmente (BAUER, 2008).

Pode-se entender o exemplo, acima citado, como auto-organização ou autopoiese, característica de uma empresa caótica (PRIGOGINE, 1996; WHEATLEY, 2006).

\section{CONCLUSÃO E CONSIDERAÇÕES FINAIS}

Os resultados finais atendem à problematização de verificar se existem elementos típicos da Teoria do Caos nos processos de planejamento em organizações, assim como se a visão, missão e objetivos consistem em atratores que evitam que a bifurcação ou ponto de ruptura se instale. Atende também ao objetivo de analisar a aplicação da teoria do Caos nas organizações, além dos específicos de analisar os conceitos da Teoria do Caos, e sua aplicação em organizações.

A pesquisa evidenciou que os dirigentes das empresas pertencentes à amostragem selecionada, em maioria predominante, entendem o Caos como falta de controle.

Durante a pesquisa, predominou a utilização de indicadores, em situações caóticas variando somente o grau de sofisticação de cada indicador apresentado. Notou-se forte indício de que existem valores limítrofes e faixas de controle, porém esses limites não foram citados. 
Um depoente afirmativa que a empresa tem que ter um sonho, e que esse sonho é um fator importante para o sucesso, que sonhos distantes não devem ser criados, porque estamos em um mundo muito dinâmico. A divisão de objetivos, sonhos ou perspectivas de futuro foi enfatizada por este executivo, que afirmou ser importante que todos remem na mesma direção. Evidencia-se a possibilidade de utilizar missão, valores, culturas como atrator estranho nas organizações (BAUER, 2008; DRAFT; LENGEL, 2001; MORGAN, 2000).

Os dez depoentes admitiram a importância e mantêm funções polivalentes, com visão geral da empresa, não descartando também a presença de especialistas para funções específicas. A importância da polivalência funcional ou redundância, nas funções em empresas complexas, é salientada por Morgan (2000), Agostinho (2003) e Nonaka e Takeuchi (1997).

A abordagem de que não temos como prevenir o dia de amanhã se enquadra na Teoria do Caos, uma vez que a imprevisibilidade é devida à dependência sensitiva às condições iniciais (DSCI) (FREITAS, 2005; ANSELMO, 2005).

\section{REFERÊNCIAS}

ANSELMO, E.. Modelo de gestão não linear: a Teoria do Caos e Complexidade aplicada à gestão de empresas de alto crescimento em ambientes dinâmicos e imprevisíveis. 2005. 155 f. Tese (Doutorado) Departamento de Administração - Programa de Pós-graduação em Administração da Faculdade de Economia, Administração e Contabilidade da Universidade de São Paulo, São Paulo, 2005. Disponível em:

<http://www.google.com.br/search?q=ANSELMO $\% 2 \mathrm{C}+$ Estev\%C3\%A3o\%3B+Modelo+de+gest\%C3\%A 3o+n\%C3\%A3o-linear\&rls=com.microsoft:en-us:IE-SearchBox\&ie=UTF-8\&oe=UTF-

8\&sourceid=ie7\&rlz=1I7RNTN_em >. Acesso em: 16 ago. 2014.

BAUER, R.. Gestão da mudança: caos e complexidade nas organizações. São Paulo: Atlas, 2008.

BERTALANFFY, L. V.. Teoria geral dos sistemas. 2. ed. Petrópolis: Vozes, 2008.

CKEIK, J.. Chaos making a new science. 18. ed. New York: Penguin Group, 2008.

DAFT, R. L.; LENGEL, R. H. O desafio do caos. In: CUNHA, M. P. et al. (Org.). Empresas, caos e complexidade. Lisboa: RH, 2001. Cap. 3.

EISENHARDT, K.M.; SCHOONHOVEN, C. B.. Organizational Growth: Linking Founding Team, Strategy. Environment and growth among. Administrative Science Quarterly, v. 35, Issue 3, p. 504-529, Sept. 1990. Disponível em:

<http://web.ebscohost.com/ehost/pdfviewer/pdfviewer?vid=2\&hid=119\&sid=fb4d7669-0a4f-4ca9-82ab1adb1d09146b\%40sessionmgr110>. Acesso em: 16 ago. 2014.

FRANKL, V. E. Um sentido para a vida. 4. ed. São Paulo: Santuário, 1989.

FREITAS, W. B. de. As teorias do caos e da complexidade na gestão estratégica. 2005. $148 \mathrm{f}$. Dissertação (Mestrado em Administração) - Universidade Municipal de São Caetano do Sul, São Caetano do Sul, 2005.

GIOVANNINI, F.; KRUGLIANSKAS, I.. Organização eficaz: como prosperar em um mundo complexo e caótico, usando um modelo de racional de gestão. São Paulo: Nobel, 2004.

GUO, X.et al. Chaos Theory as a Lens for Interpreting Blogging. Journal of Management Information Systems, [S. 1.], v. 26, Issue 1, p. 101-127, summer 2009. Disponível em:

<http://web.ebscohost.com/ehost/pdfviewer/pdfviewer?vid=2\&hid=110\&sid=6c496f1f-1a1b-4418-be6bc410a72d6efc\%40sessionmgr113>. Acesso em: 16 ago. 2014. 
GUO, X.et al.. Chaos Theory as a Lens for Interpreting Blogging. Journal of Management Information Systems, [S. 1.], v. 26, Issue 1, p. 101-127, summer 2009. Disponível em:

<http://web.ebscohost.com/ehost/pdfviewer/pdfviewer?vid=2\&hid=110\&sid=6c496f1f-1a1b-4418-be6bc410a72d6efc\%40sessionmgr113>. Acesso em: 16 ago. 2014.

HUNG, S.C.; TU, M.F.. Is Chaos Theory Useful In Describing Technological Change? Academy of Management Proceedings, Chicago, p. 1-6, 2009. Disponível em:

<http://web.ebscohost.com/ehost/pdfviewer/pdfviewer?vid=2\&hid=112\&sid=b6ba71ee-3c90-49df-8ad8010b922a366f\%40sessionmgr114 >. Acesso em: 16 ago. 2014.

MATOS, J. G. R.; MATOS, R.M. B.; ALMEIDA, J. R.de. Análise do ambiente corporativo: do caos organizado ao planejamento estratégico das organizações. Rio de Janeiro: E-papers, 2007.

MARIOTTO, F. L.. Mobilizando estratégias emergentes. Revista de Administração Empresarial, São Paulo, v. 43, n. 2, p. 78-93, abr./maio/jun. 2003.

MCBRIDE, N.. Chaos theory as a model for interpreting information systems in organizations. Information Systems Journal, [S. 1.], v. 15, Issue 3, p. 233-254, July 2005. Disponível em: <http://web.ebscohost.com/ehost/pdfviewer/pdfviewer?vid=2\&hid=104\&sid=f4bd2419-25e9-4d83-8985e8e3dd586669\%40sessionmgr111>. Acesso em: 16 ago. 2014.

MORGAN, G.. Imagens da Organização. São Paulo: Atlas, 2009.

PRIGOGINE, I.. O fim das certezas: tempo, caos e as leis da natureza. São Paulo: Editora da Universidade Estadual Paulista, 1996.

SMITH, A.. Three scenarios for applying chaos: theory in consumer research. Journal of Marketing Management, [S. 1.], v. 18, Issue 5/6, p. 517-531, July 2002. Disponível em:

$<$ http://web.ebscohost.com/ehost/pdfviewer/pdfviewer?vid=2\&hid=110\&sid=3ee93435-9db0-4c6e-a08252c46ab0616d\%40sessionmgr11>. Acesso em: 16 ago. 2014.

THIETART, R. A.; FORGUES, B. Chaos Theory and Organization. Organization Science, [S. 1.], v. 6, Issue 1, p.19-31. Jan./Feb. 1995. Disponível em:

<http://web.ebscohost.com/ehost/pdfviewer/pdfviewer?vid=2\&hid=107\&sid=fbd8f0e2-bd8b-43ee-a70921d5eeb0e072\%40sessionmgr110>. Acesso em: 16 ago. 2014.

WHEATLEY, M.J. Liderança e a nova ciência: descobrindo a ordem num mundo caótico. 8. ed. São Paulo: Cultrix, 2006.

WHEATLEY, M.J.; ROGERS, M.L.. Um caminho mais simples. 9. ed. São Paulo: Cultrix, 2000.

WILBER, K.. Uma teoria de tudo. 3. ed. São Paulo: Cultrix, 2007. 